\title{
Os Direitos Humanos da Tributação - um Caso Concreto: 0 direito à dedução integral dos gastos com medicamentos da base de cálculo do imposto sobre a renda
}

\section{Taxation Human Rights - a Concrete Case: the right to the full income tax deduction of expenses with medicines}

\author{
Carlos Araujo Leonetti \\ Universidade Federal de Santa Catarina, Florianópolis - SC, Brasil
}

Resumo: $\mathrm{O}$ presente artigo aborda um aspecto específico relacionado aos direitos humanos da tributação; qual seja, o direito à dedução integral dos gastos com medicamentos da base de cálculo do imposto sobre a renda. Após uma breve introdução ao tema dos direitos humanos da tributação, que parte de uma visão relativamente nova no direito universal, faz-se uma incursão no imposto sobre a renda - pessoa física, revisitando-se seus conceitos básicos e princípios fundamentais. É apresentado, também, um brevíssimo histórico do IRPF no Brasil, a fim de situar melhor a matéria em discussão. Na sequência, enfrenta-se a questão atinente às deduções permitidas, na base de cálculo do imposto. Finalmente, analisa-se a possível inclusão dos gastos com medicamentos entres essas deduções, concluindo que se revela um imperativo de Justiça e de respeito à Constituição.

Palavras-chave: Direitos Humanos da Tributação. Imposto sobre a Renda. Dedutibilidade dos Gastos com Medicamentos.
Abstract: This article is intended to address a specific aspect related to the taxation human rights: the right to full deduction of expenses with medicines from the basis for calculating the income tax. After a brief introduction to the topic of taxation human rights a relatively new vision in universal law, the article makes a foray into the income tax-individual, revisiting its basic concepts and principles. Is presented, also, a brief history of the IRPF in Brazil, in order to better situate the subject in focus. In the sequel, the article faces the question about the deductions allowed, on the basis of calculation of the tax. Finally, the article analizes the possible inclusion of spending on medicines among these deductions, concluding that it is an imperative of Fairness and respect to the Constitution.

Keywords: Taxation Human Rights. Income Tax. Medicine Expenses Deductions.

Recebido em: 22/10/2013

Revisado em: 07/04/2014

Aprovado em: 11/04/2015 


\section{Introdução}

Nas últimas décadas, a tributação vem sendo vista não apenas como um instrumento de arrecadação de recursos para os cofres públicos, função por si só meritória, mas também como uma forma de garantir direitos fundamentais do cidadão. Este último papel cumprido pelos tributos é conhecida, na doutrina, por "direitos humanos da tributação".

Com efeito, tributaristas, no Brasil, como Alberto Nogueira (1997), Carlos Araujo Leonetti (2003), Paulo Caliendo (2009, p. 203-237; 267-268) e Ricardo Lobo Torres (1999, p. 7-35) estão, há algum tempo, mostrando essa outra face da tributação. Essa atuação da tributação como garantidora dos direitos humanos pode ocorrer, essencialmente, de duas formas:

a) Fazendo com que os tributos ditos fiscais, i.e, aqueles cuja função precípua é a de arrecadação, sejam exigidos em estreita sintonia com os princípios tributários plasmados na Constituição da República, como os da legalidade, da tipicidade, da isonomia, da capacidade contributiva e da vedação de tributo confiscatório.

b) Utilizando-se, adequadamente, a chamada tributação extrafiscal, em que a arrecadação não é o mais importante, mas, sim, a indução de determinados comportamentos, para a consecução de políticas públicas.

Neste artigo, analisar-se-á um caso concreto relacionado com um tributo predominantemente fiscal, a saber, o imposto sobre a renda das pessoas físicas - Imposto de Renda de Pessoa Física (IRPF).

\section{O IRPF como Instrumento de Justiça Social}

Conforme Carlos Araujo Leonetti (2003, p. 177-206) procurou demonstrar, o IRPF brasileiro é dotado de enorme potencialidade para atuar como instrumento de Justiça Social. Infelizmente, esse potencial não vem sendo devidamente utilizado como se esperava, deixando lacunas a serem preenchidas. 
Com efeito, apesar de o IRPF revestir natureza eminentemente fiscal, é inegável que esse imposto também é dotado de apreciável vocação extrafiscal. Tanto no Brasil, como em outros países, o IRPF é empregado, em maior ou menor grau, como tributo extrafiscal, visando estimular, ou desestimular, determinados comportamentos.

John Rawls (1971, p. 306-308), filósofo americano e Professor na Universidade Harvard, em sua obra clássica, já na década de 1970, preconizava a tributação da renda de forma indireta, por meio da "[...] tributação proporcional sobre as despesas, permitindo-se a dedução de algumas despesas, como as relativas a dependentes". Isto é, vê-se que, embora Rawls sugerisse a tributação da renda de forma indireta, via tributação do consumo, ele defendia que houvesse a dedução de alguns dos gastos em que o contribuinte incorreu.

\section{Uma breve Revisão do IRPF no Brasil}

No Brasil, conforme ensina Aliomar Baleeiro (2001, p. 282), os primeiros estudos e projetos visando à criação de um imposto sobre a renda datam do século XIX. Entre os diversos homens públicos que defenderam a introdução da tributação da renda em terras brasileiras destacam-se os Viscondes de Jequitinhonha e de Ouro Preto, o Barão do Rosário, o Conselheiro Lafayette e Ruy Barbosa.

A primeira Constituição brasileira, a de 1824, silenciou a respeito da discriminação das competências tributárias entre os governos central, das províncias, dos municípios e das vilas, uma vez que o poder físcal se concentrava na pessoa do Imperador (MORAES, 1994, p. 119). Em suma, segundo afirma Rubens Gomes de Sousa (1963, p. 10), "[...] a Constituição imperial de 1824 mantinha muito pouco sobre tributação e absolutamente nada sobre tributos provinciais e locais. As Províncias figuravam no orçamento imperial simplesmente como dotações de despesas".

A primeira Constituição republicana, por seu turno, preocupada com o modelo de Estado federal que implantou, cuidou de discriminar com clareza as competências tributárias da União (art. $7^{\circ}$ ) e dos Estados $\left(\right.$ art. $\left.9^{\circ}\right)$. Quanto aos tributos de competência dos Municípios, a Carta de 
1891 foi absolutamente omissa, deixando, assim, aos Estados a tarefa de regular a matéria.

Já a Carta de 1934 explicitou os tributos, inclusive os impostos, que os Municípios poderiam instituir (art. 13, par. $2^{\circ}$ ), a exemplo do que fez com respeito à União (art. $6^{\circ}$ ) e aos Estados (art. $8^{\circ}$ ), além de prever a criação de impostos residuais (art. 10, VII) e a cobrança de contribuição de melhoria, pela União, Estados ou Municípios (art. 124).

A Constituição de 1946 prosseguiu nessa mesma linha, adotando, porém, uma discriminação de competências tributárias dotada de maior rigidez, na medida em que utilizou terminologia tecnicamente mais precisa, inclusive no tocante aos nomen juris dos tributos elencados. (MORAES, 1994, p. 142)

A situação foi substancialmente modificada com a Emenda Constitucional n. 18 , de $1^{\circ}$ de dezembro de 1965 , já durante o regime militar implantado a partir de abril de 1964. Essa Emenda, no dizer de Bernardo Ribeiro de Moraes (1994, p. 153), “[...] trouxe ao país uma autêntica reforma tributária, fazendo revisão e mudança completas no antigo sistema tributário". Tal afirmativa revela-se plenamente consoante à realidade: desde 1891, a discriminação das competências tributárias, nas Constituições brasileiras, vinha mantendo a mesma estrutura básica, com pequenas modificações. Um dos grandes méritos do sistema tributário nacional introduzido pela Emenda n. 18/65 foi, sem dúvida, a adoção de critério econômico para classificação dos impostos, i.e, discriminou-os com referência às suas bases econômicas, facilitando-lhes assim a operacionalização. Entretanto, a maior virtude da reforma tributária operada pela Emenda n. $18 / 65$ talvez tenha sido a de permitir que o princípio federativo pudesse ser efetivamente implementado, na medida em que as competências tributárias dos entes federativos restaram explicitadas. Ives Gandra Martins, (1989, p. 21, grifos nossos) lembra que "[...] a Federação, portanto, constituiu-se no primeiro elemento escultor do sistema (tributário nacional)".

A Constituição de 1967, por sua vez, tanto em sua redação original como na que lhe foi dada pela Emenda n. 1/69, não promoveu alterações de vulto no sistema preconizado pela Emenda n. 18/65. 
No que tange à tributação da renda, muito embora a Constituição de 1891 não a tenha expressamente previsto, permitiu sua instituição, pela União e pelos Estados, pela via da competência concorrente e cumulativa, expressa em seu artigo 12 ${ }^{1}$. Apesar de estar previsto na Lei n. 4.625, de 31 de dezembro de 1922, que dispunha sobre o orçamento para o exercício seguinte, o imposto sobre a renda somente foi instituído em 31 de dezembro de 1923, pela Lei n. 4.783, igualmente orçamentária, sendo que o primeiro Regulamento foi aprovado pelo Decreto n. 16.581, de 4 de setembro de 1924. (CARVALHO, [196?], p. 349)

Durante muitos anos, o imposto sobre a renda brasileiro adotou o modelo cedular tradicional. Inicialmente, os rendimentos tributáveis eram classificados em quatro categorias ou cédulas, às quais a Lei Orçamentária de 31 de dezembro de 1924 acresceu mais uma. Segundo Baleeiro, os rendimentos eram "[...] classificados em categorias e tributados proporcionalmente. A soma dos rendimentos constituía a renda bruta, que, depois de certas deduções, sofria o imposto complementar progressivo". (BALEEIRO, 2001, p. 282)

Em 1988, a Lei n. 7.713, de 22 de dezembro, introduziu a sistemática de apuração mensal do imposto devido pelas pessoas físicas e suprimiu a classificação de rendimentos em cédulas, adotando o assim chamado sistema global de apuração, ainda que não em sua forma pura.

As modificações introduzidas pela Lei n. 7.713/88 conferiram maior simplicidade à sistemática de apuração e declaração do imposto, mas comprometeram seriamente o caráter pessoal e, por conseguinte, o respeito ao princípio da capacidade contributiva. (MACHADO, 2000, p. 254)

A partir do ano-calendário de 1989, a tributação da renda das pessoas físicas passou a obedecer ao assim chamado sistema em bases correntes, versão nacional do Pay-As-You-Earn já adotado em outros países, pelo qual o tributo é pago à medida que a renda é auferida.

\footnotetext{
1 "Art. 12 - Além das fontes de receita discriminadas nos arts. 7o. e 9o., é lícito à União, como aos Estados, cumulativamente ou não, criar outras quaisquer, não contravindo o disposto nos arts. $7^{\circ}, 9^{\circ}$ e 11, n. $1 . "$
} 


\section{Os Princípios Retores do IRPF}

Como todo e qualquer instituto jurídico e, por conseguinte, os tributos, o IRPF resta informado por diversos princípios, plasmados no texto constitucional.

A seguir, discorrer-se-á sobre alguns desses princípios:

\subsection{Princípio da Igualdade (ou isonomia) Tributária}

Esse princípio, que estava implícito (BALEEIRO, 2001, p. 520) no texto constitucional anterior, hoje é expresso no artigo 150, II, da Constituição ${ }^{2}$. Em decorrência dessa norma, que por seu turno é corolário do princípio constitucional geral segundo o qual "[...] todos são iguais perante a lei, sem distinção de qualquer natureza [...]" (Constituição, art. $5^{\circ}$, caput, primeira parte), tanto o legislador quanto o aplicador da lei não podem conferir tratamento tributário diferente aos contribuintes que se encontrem em situação equivalente.

A origem desse princípio remonta à Europa do século XVIII, quando ainda subsistiam alguns privilégios de nascimento (MORAES, 1994, p. 111). Não por acaso, a igualdade figurava no lema ${ }^{3}$ dos revolucionários que galgaram o poder na França em 1789 e foi contemplada no primeiro artigo da Declaração dos Direitos do Homem e do Cidadão, de 26 de agosto daquele ano, assim como nas Constituições francesas que se seguiram. (BALEEIRO, 2001, p. 520)

Na lição de Bernardo Ribeiro de Moraes (1994, p. 113), o princípio da igualdade jurídica, do qual se origina a isonomia tributária, determina que todos sejam iguais perante a lei desde que sejam respeitadas as dife-

\footnotetext{
2 “Art. 150 - Sem prejuízo [...] é vedado à União, aos Estados, ao Distrito Federal e aos Municípios..

II - instituir tratamento desigual entre contribuintes que se encontrem em situação equivalente, proibida qualquer distinção em razão de ocupação profissional ou função por eles exercida, independentemente da denominação jurídica dos rendimentos, títulos ou direitos;"

3 Em francês: "liberté, egalité, fraternité".
} 
renças existentes, de sorte que somente as pessoas em circunstâncias e condições iguais é que devem receber o mesmo tratamento.

O princípio da igualdade tributária exige, assim, que a lei, tanto ao ser elaborada quanto ao ser aplicada, respeite duas exigências básicas, segundo Carrazza (1994, p. 61), que são:

$1^{\text {a) }}$ não discrimine os contribuintes que se encontrem em situação equivalente; e

$2^{\text {a) }}$ discrimine, na medida de suas desigualdades, i.e, segundo a capacidade contributiva de cada um, os contribuintes que não se encontrem em situação equivalente.

Essa necessidade de conferir tratamento distinto aos contribuintes que se encontram em situação desigual decorre do fato de que, se tal não for feito, invariavelmente haverá ferimento ao princípio da igualdade jurídica, uma vez que se estará tratando igualmente os desiguais. Por outro lado, tal discriminação não pode ser feita de modo não criterioso, sob pena de não se alcançar o objetivo colimado: há que ser balizada pela capacidade contributiva.

Em sede de imposto sobre a renda, o princípio da igualdade é concretizado mediante o emprego dos critérios, ou princípios, da generalidade, da universalidade e da progressividade, os quais serão examinados posteriormente.

\subsection{Princípio da Capacidade Contributiva}

O princípio da isonomia tributária completa-se com o da chamada capacidade contributiva. Há quem sustente inclusive que a igualdade absorveria a capacidade contributiva, conforme anota Luciano Amaro (2012, p. 164), citando, entre outros, Alberto Xavier, Geraldo Ataliba, Paulo de Barros Carvalho e Roque Carrazza. Na lição de Sacha Calmon Navarro Coêlho (1990, p. 329), a juridicidade da capacidade contributiva resulta "[...] do lado positivo do dever de igualdade: o dever imposto ao legislador de distinguir disparidades". No mesmo sentido é o escólio de Luciano Amaro (2012, p. 164), para quem o princípio “[...]corresponde a um dos aspectos da igualdade, que é o tratamento desigual para os desiguais”. 
Por esse princípio - cujo alcance se cingiria, à luz da Constituição, aos impostos - estes, sempre que possível, “[...] terão caráter pessoal e serão graduados segundo a capacidade econômica do contribuinte" (Constituição, art. 145, par. $1^{\circ}$ ) Apesar de o texto constitucional usar a expressão "capacidade econômica", o princípio é mais conhecido como o da "capacidade contributiva". Ives Gandra Martins critica duramente o uso da expressão "capacidade econômica" pelo constituinte de 1988, pois considera que o postulado se refere à capacidade contributiva das pessoas, que com aquela não se confundiria (MARTINS, p. 76-77). Crê-se que a razão assiste a Martins: a expressão capacidade econômica parece refletir mais a situação patrimonial do contribuinte do que suas possibilidades de desembolso que, estas sim, externariam sua efetiva capacidade de pagar tributos ${ }^{4}$.

O princípio da capacidade contributiva exige que o contribuinte de impostos, como o incidente sobre a renda, suporte carga tributária compatível com sua situação pessoal, cumprindo assim função dúplice:

$1^{\text {a) }}$ distribuir a carga tributária global entre os contribuintes de acordo com a aptidão de cada um de pagar tributos;

$2^{a}$ ) impedir que a carga tributária individual se torne insuportável, de modo a comprometer a subsistência do contribuinte e de sua família.

Nesse sentido, o princípio está ligado à ideia de garantia do mínimo social, mínimo existencial, ou ainda mínimo vital, isto é, o postulado impediria que alguém fosse submetido a uma carga tributária tal que o proibisse, e à sua família, de desfrutar condições mínimas de vida digna, relacionando-se, destarte, com o princípio da vedação de tributo confiscatório. Assim, o princípio pode, em alguns casos, fundamentar a isenção tributária, como ocorre no IRPF, por exemplo, relativamente aos contribuintes com renda tributável abaixo de determinado limite.

\footnotetext{
4 Assim, v.g., uma senhora viúva que (sobre)viva da minguada pensão deixada pelo finado marido e seja proprietária de um único imóvel de valor de mercado elevado mas, que não gera receita, disporia de capacidade econômica mas não de capacidade contributiva.
} 
Ricardo Lobo Torres (1999, p. 334) observa, com muita felicidade, que o princípio da capacidade contributiva consiste na verdade em legitimar a tributação, na medida em que gradua a carga tributária individual, de modo que os ricos paguem mais e os pobres, menos.

No que diz respeito à expressão "sempre que possível", do artigo 145, par. $1^{\circ}$, da Constituição, a doutrina diverge: para uns, a expressão referir-se-ia, apenas, ao caráter pessoal dos impostos; para outros, estender-se-ia também à capacidade contributiva. Ives Gandra Martins (1989, p. 76-77) defende a primeira posição, pois entende que nem todos os impostos se prestam, por suas características, ao atendimento do requisito da pessoalidade, enquanto que a capacidade contributiva deveria ser respeitada em todos os tributos (e, em especial, em todos os impostos), sob pena de permitir-se a tributação com efeito de confisco. Já Luciano Amaro (2012, p. 164) vê a ressalva mirar tanto a pessoalidade como a capacidade contributiva, porquanto, “[...] dependendo das características de cada imposto, ou da necessidade de utilizar o imposto com finalidades extrafiscais, esses princípios podem ser excepcionados". A posição defendida por Amaro nos parece ser a que melhor se coaduna com o espírito da Carta de 1988 e com a realidade tributária brasileira.

Alfredo Augusto Becker (1972, p. 437) anota que o princípio da capacidade contributiva é antiquíssimo, tendo se originado do ideal de justiça distributiva preconizado pelos filósofos gregos e mais tarde adotado pela filosofia escolástica. Acompanha-o Alberto Nogueira (1997, p. 101), o qual lembra que (São) Tomás de Aquino, grande expoente do escolasticismo, defendeu a adoção do postulado. Adam Smith (1983, p. 485) também defendeu esse princípio ao asseverar que "[...] os súditos de todos os Estados devem contribuir para a manutenção do Governo, tanto quanto possível, em proporção das respectivas capacidades". Os revolucionários franceses de 1789 igualmente o abraçaram, fazendo-o constar expressamente (no artigo 13) da Declaração Universal dos Direitos do Homem e do Cidadão. (NOGUEIRA, 1997, p. 100) 


\subsection{Princípio da Pessoalidade ou Personalização}

O princípio da capacidade contributiva guarda íntima relação com o assim chamado princípio da personalização, ou da pessoalidade. Há quem inclusive veja a personalização como uma das faces da capacidade contributiva (AMARO, 2012, p. 165). Não seria por mero acaso, assim, que ambos os princípios figuram no mesmo dispositivo constitucional. (art. 145, par. $1^{\circ}$ ). Na verdade, pode-se dizer que um completa o outro, de sorte que nenhum deles, isoladamente, revelar-se-ia apto a produzir os efeitos esperados.

A personalização, que deve, tal como a capacidade contributiva, ser aplicada aos impostos sempre que possível, dirige-se ao legislador e implica a estruturação do tributo de modo que determinadas características do contribuinte, tais como renda, patrimônio, número de dependentes, despesas médicas e com instrução, estado de saúde, etc., sejam tomadas em consideração. Assim, a personalização permite que a capacidade contributiva seja eficazmente respeitada, conferindo concretude ao princípio da igualdade.

\subsection{Princípios (ou critérios) da Generalidade e da Universalidade}

Tais princípios, os quais o legislador constituinte preferiu denominar de critérios informativos do imposto sobre a renda (Constituição, art. 153 , par. $\left.2^{\circ}, I\right)$ conforme já visto encontram-se também intimamente relacionados com o princípio da igualdade. Pode-se dizer que a igualdade, em termos de tributação da renda, somente é concretizada se tais princípios (ou critérios) forem devidamente respeitados.

O princípio da generalidade exige que todas as pessoas se sujeitem ao imposto sobre a renda, ao passo que a universalidade importa em submeter todas as manifestações de renda do contribuinte à imposição tributária ${ }^{5}$. Em outras palavras, o imposto deve incidir sobre todas as rendas,

\footnotetext{
5 Anote-se, porém, que a doutrina não é unânime quanto ao significado das expressões generalidade e universalidade. Para Sacha Calmon Navarro Coêlho, por exemplo, a generalidade implicaria a incidência do tributo "sobre todos", ao passo que a universalidade exigiria o seu pagamento "por todos". (COÊLHO, 1990, p. 206)
} 
de todas as pessoas, ressalvadas as hipóteses em que o interesse público ou outro princípio constitucional, como o da capacidade contributiva ${ }^{6}$, justificar um tratamento diferenciado.

Ricardo Lobo Torres (1999, p. 375-380; 387-390) observa que, desde o início da tributação da renda, no Brasil, algumas categorias profissionais tentaram se furtar à submissão integral de sua remuneração ao imposto, às vezes com sucesso. Dentre essas categorias destacam-se as dos magistrados, parlamentares, jornalistas, escritores, professores, agentes do fisco e militares. Até 1937, por influência da jurisprudência americana, o Supremo Tribunal Federal entendeu que a remuneração dos magistrados, assim como as dos demais agentes públicos, gozava de imunidade intergovernamental recíproca. A partir de 1938, a orientação do STF mudou, acompanhando os ventos que sopravam do norte $\mathrm{e}^{\text {" }}[$ [... acatando as determinações do regime autoritário [...]” (TORRES, p. 377) implantado no ano anterior com o advento do "Estado Novo". Com a promulgação da Carta de 1946, o Supremo voltou a reconhecer a imunidade dos magistrados quanto ao imposto sobre a renda, ao argumento de que a incidência desse tributo não estaria mais ressalvada do princípio da irredutibilidade dos vencimentos dos juízes, porquanto esse tributo não mais revestiria a condição de imposto geral ${ }^{8}$. Posteriormente, a Emenda Constitucional n. 9/64 previu expressamente a sujeição dos rendimentos dos magistrados ao imposto sobre a renda. A Constituição de 1967, na redação que lhe foi conferida pela Emenda 1/69, deixou claro, ao dispor sobre a irredutibilidade dos vencimentos dos magistrados, que estes estavam "[...] sujeitos, entretanto, aos impostos gerais, inclusive o de renda" (Constituição de 1967/69, art. 113, III). Em 1983, porém, ao apagar das luzes do regime militar, o Decreto-Lei n. 2.019, de 28 de março, excluiu expressamente

\footnotetext{
6 Seria o caso da isenção concedida aos contribuintes de baixa renda.

7 Na década de 1930, a Suprema Corte Americana começou a reverter a orientação até então adotada. Vide sobre este tema o item 3.1.3 do Capítulo 3.

8 RE 43.941 - Tribunal Pleno - j. 13.1 .60 - Rel. Min. Luiz Gallotti - RTJ 12, 197. A tese acolhida pela Corte foi a de que, como a Constituição imunizou expressamente os direitos autorais e a remuneração de professores e jornalistas em face do IRPF (art. 203), este perdera a característica de imposto geral e, assim, não estaria mais excepcionado do princípio da irredutibilidade de vencimentos dos magistrados (art. 95, n=3.)
} 
da incidência do IRPF a verba de representação dos magistrados prevista no art. 65 , par. $1^{\circ}$, da Lei Complementar n. 35/79. Com a entrada em vigor da Constituição de 1988, os privilégios tributários dos magistrados ${ }^{9}$, assim como os das demais categorias profissionais, foram abolidos. Com efeito, além da expressa previsão da aplicação, ao imposto sobre a renda, dos critérios da generalidade e universalidade, no artigo 153 , par. $2^{\circ}, \mathrm{I}$, o constituinte cuidou de deixar clara sua repugnância por qualquer forma de privilégio quanto à submissão integral dos rendimentos à tributação, no artigo 150, II, in fine, que veicula o princípio da igualdade tributária, e em diversos outros dispositivos ${ }^{10}$. Vale lembrar que o artigo 150, II, ao dispor sobre o princípio da igualdade tributária, proíbe "[...] qualquer distinção em razão de ocupação profissional ou função por eles [os contribuintes] exercida, independentemente da denominação jurídica dos rendimentos, títulos ou direitos". A expressa remissão à denominação jurídica dos rendimentos, títulos e direitos visou coibir a prática - infelizmente comum entre nós - de denominar parcelas remuneratórias como "ajudas”, "auxílios" ou "verbas de representação", pretendendo assim fugir à tributação.

\section{A Dedução de Certas Despesas da Base de Cálculo do IRPF}

A maioria dos países em que há tributação da renda da pessoa física adota o sistema de dedutibilidade de certas despesas, da base de cálculo do imposto.

Isso significa que o tributo não incide a renda auferida para fazer frentes a tais despesas. Esta técnica é possível porque, "no frigir dos ovos", como se diz, renda e consumo se confundem. Essa assertiva decorre da constatação que a renda de alguém, em determinado período de tempo, será transformada em aumento do seu patrimônio, ou em consumo.

\footnotetext{
9 O art. 95, III, ao dispor sobre a irredutibilidade dos vencimentos dos magistrados, ressalva a incidência do imposto sobre a renda.

10 Por exemplo, nos arts. 27, par. 2º; 28, par. 2º; 29, V e VI; 37, XV; 48, XV; 49, VII e VIII; 95, III; 128, par. 5, I, $c$, nos quais se deixa claro que a remuneração dos agentes públicos está sujeita ao IRPF, e 151, II, que proíbe à União tributar a remuneração e os proventos dos agentes públicos de Estados, Distrito Federal e Municípios em níveis superiores aos que fixar para os seus.
} 
Não é outra a fundamentação do conceito de renda de Haig-Simons: renda é aumento do potencial de consumo de alguém, durante certo lapso temporal. (LEONETTI, C. A., 2003, p. 22)

A doutrina, tanto pátria como estrangeira, diverge quanto às razões que determinam a dedutibilidade de certos gastos. Acredita-se nas razões de duas ordens:

a) Assegurar o cumprimento do princípio da capacidade contributiva (vigente no Brasil e em outros países.

b) Estimular determinados comportamentos, pelo contribuinte, que o Estado entende relevantes, à luz das políticas públicas adotadas.

Assim, ao assegurar a dedução dos gastos com saúde (exceto medicamentos), educação, dependentes, etc. o Estado brasileiro está reconhecendo que essas despesas, de resto involuntárias, comprometem sua capacidade contributiva.

Com efeito, o contribuinte que tem dependentes, e com os quais tem gastos consideráveis relativamente com a saúde e a educação, provavelmente, não poderá pagar imposto sobre a renda, no mesmo valor em que outro cidadão, com a mesma renda bruta, mas sem dependentes, o faria.

Resta claro, assim, que a não possibilidade dessas deduções comprometeria, irremediavelmente, a capacidade contributiva do cidadão.

\section{A Inconstitucionalidade da Não Dedutibilidade das Despesas com Aquisição de Medicamentos e seu Impacto nos Direitos Humanos da Tributação}

Atualmente, a legislação permite que o contribuinte, pessoa física, deduza, da base de cálculo do imposto, algumas despesas. A maioria delas está sujeita a limite. As despesas com saúde, em tese, não estão sujeitas a limite. Entretanto, os gastos com saúde não incluem a aquisição de medicamentos, exceto se esse valor integrar a conta hospitalar. 
Esse quadro revela, por si só, flagrante desrespeito da lei aos princípios constitucionais tributários, como o da isonomia, o da capacidade contributiva, o da pessoalidade e o da dignidade da pessoa humana.

Com efeito, se o contribuinte pode abater as despesas em que incorreu com médicos, dentistas e outros profissionais de saúde, sem obedecer a limite, uma vez que tais despesas se revelam involuntárias e absolutamente necessárias, não se revela lógico proibir o abatimento de gastos com medicamentos.

Ora, tanto as despesas com profissionais de saúde, como as com compra de medicamentos, tem o mesmo fim: a preservação da saúde do contribuinte, e/ou de seus dependentes.

Se assim o é, como justificar que as primeiras sejam dedutíveis e as outras, não? Pior ainda é aceitar a solução dada pela lei, segundo a qual se o contribuinte estiver internado em estabelecimento hospitalar, e o preço dos medicamentos forem incluídos na respectiva conta, estes serão dedutíveis, isto é, a legislação obriga, ou, pelo menos, estimula, que o contribuinte/dependente se interne em nosocômio para que possa deduzir o gasto com remédios. Em outras palavras: o contribuinte internado tem um tratamento tributário mais favorecido do que o não internado, sem que se vislumbre qualquer razão lógica ou jurídica para tal discriminação.

De outra banda, a exclusão dos gastos com medicamentos do rol das despesas dedutíveis fere, também, o princípio da isonomia, uma vez que os contribuintes que têm gastos com profissionais de saúde, v.g, têm direito ao seu abatimento, enquanto o cidadão que gasta com remédios não pode fazê-lo.

Por derradeiro, o princípio da dignidade da pessoa humana resta desobedecido, pela situação em foco, uma vez que, ao negar ao contribuinte o direito à dedução dos gastos com remédios, gastos estes de caráter obrigatório, contribui para que não seja respeitado o chamado mínimo social, ou vital, ou existencial.

Para Ricardo Lobo Torres (1999, p. 144-145), embora seja difícil conceituar mínimo existencial, certo é que guarda estreita relação com a 
pobreza, isto é, a hipossuficiência do cidadão, que se vê incapaz de proporcionar a si próprio,e à sua família, condições de vida dignas.

Nessa linha de raciocínio, ao contribuir para agravar as más condições de vida de boa parte dos cidadãos, que são obrigados a consumir medicamentos, sem poder abater esses gastos na base de cálculo do imposto de renda devido.

\section{A Possibilidade de Reconhecimento, na via Judicial, do Direito à Dedução dos Gastos com Medicamentos}

Constatado que a dedução das despesas com compra de remédios se revela direito constitucional do contribuinte, é forçoso reconhecer que este pode ser reconhecido pelo Poder Judiciário, se provocado for, e mediante a via judicial adequada, ainda que inexista previsão legal. Isso porque é indubitável que o Judiciário não só pode, mas deve, intervir, quando um direito constitucionalmente assegurado é sonegado pelo Poder Executivo, independentemente de haver lei reguladora.

O Supremo Tribunal Federal tem exercitado esse poder/dever, ainda que com cautela, como se recomenda, em casos desta natureza:

a) o direito do servidor público à greve;

b) o direito à união estável homoafetiva, assim como ao casamento homoafetivo;

c) a descriminalização do aborto em caso de feto anencéfalo;

d) o uso de células-tronco para pesquisas, dentre outros.

Em todas essas situações inexistia, à época, lei assegurando e regulamentando o respectivo direito e, nem por isso, vingou a tese, levantada por alguns, de que o Poder Judiciário estaria invadindo a seara de ação do Legislativo. Prevaleceu, acertadamente, a tese de que a inércia do Legislativo em editar lei disciplinando direito previsto na Carta Magna não poderia prejudicar os destinatários da norma constitucional.

Registre-se, por oportuno que há, atualmente, projetos de lei, tramitando no Congresso Nacional, versando a dedução dos gastos com remédios. 
Contudo, enquanto nenhum desses projetos for efetivamente convertido em lei, o Poder Judiciário pode, e deve, reconhecer o direito do contribuinte à dedução de seus gastos com medicamentos, da base de cálculo do IRPF.

\section{Conclusão}

Com o presente artigo, buscou-se mostrar que o contribuinte brasileiro faz jus à dedução, da base de cálculo do IRPF, dos gastos com compra de medicamentos, à luz do disposto na Constituição da República.

Mostrou-se, ainda, que, à míngua de lei reconhecendo e regulamentando o exercício de tal direito, o contribuinte está legitimado a buscar a chancela do Poder Judiciário, por meio da ação adequada, sem que isso configure exorbitância da competência daquele. Isso porque não é razoável que direito fundamental do cidadão, no caso, ser tributado conforme sua capacidade contributiva e situação pessoal, não seja respeitado por ausência de lei a respeito.

Se a falta de lei justificasse o desrespeito a preceito fundamental, estar-se-ia retirando da Carta Magna significativa parcela de seu poder.

\section{Referências}

AMARO, Luciano. Direito tributário brasileiro. 18. ed. São Paulo: 2012.

BALEEIRO, Aliomar. Direito tributário brasileiro. 11. ed. Atualizada por Misabel Abreu Machado Derzi. Rio de Janeiro: Forense, 2001.

. Limitações constitucionais ao poder de tributar. 7. ed. Atualizada por Misabel Abreu Machado Derzi. Rio de Janeiro: Forense, 2001.

BASTOS, Celso Ribeiro. Curso de direito financeiro e direito tributário. São Paulo: Saraiva, 1991. 
BECKER, Alfredo Augusto. Teoria geral do direito tributário. 2. ed. São Paulo: Saraiva, 1972.

CARRAZZA, Roque Antonio. Curso de direito constitucional tributário. 6. ed. São Paulo: Malheiros, 1994.

CARVALHO, A. A. Contreiras de. Doutrina e aplicação do direito tributário. 2. ed. Rio de Janeiro: Freitas Bastos [196-?].

COÊLHO, Sacha Calmon Navarro. Comentários à Constituição de 1988: sistema tributário. Rio de Janeiro: Forense, 1990.

LEONETTI, Carlos Araujo. O imposto sobre a renda como instrumento de justiça social. Barueri, SP: Manole, 2003.

MACHADO, Hugo de Brito. Curso de direito tributário. 18. ed. São Paulo: Malheiros, 2000.

MARTINS, Ives Gandra. Sistema tributário na Constituição de 1988. São Paulo: Saraiva, 1989.

MORAES, Bernardo Ribeiro de. Compêndio de direito tributário. 2. ed. Rio de Janeiro: Forense, 1994.

NOGUEIRA, Alberto. A reconstrução dos direitos humanos da tributação. Rio de Janeiro: RENOVAR, 1997.

RAWLS, John. A Theory of justice. ed. rev. Cambridge, MA: Harvard University Press, 1999. (impressão 2000)

SMITH, Adam. Inquérito sobre a natureza e as causas da riqueza das nações. Lisboa: C. Gulbenkian, 1983.

SOUSA, Rubens Gomes de. A evolução do conceito de renda tributável. Revista de Direito Público, Londrina, PR, n. 14, p. 339-346, out.-dez. 1970 .

. O imposto de renda e os créditos bancários vinculados. Revista de Direito Público, Londrina, PR, n. 18, p. 335-350, out.dez. 1971.

. O sistema tributário federal. In: MINISTÉRIO da Fazenda. O Sistema fazendário. Brasília, DF: Ministério da Fazenda, 1963. 
TORRES, Ricardo Lobo. Os direitos humanos e a tributação: imunidades e isonomia. Rio de Janeiro: RENOVAR, 1995.

Carlos Araújo Leonetti é bacharel em Direito pela Universidade Federal de Santa Catarina (1992); mestre em Direito pela mesma Universidade (1998); e doutor em Direto pela Universidade Federal de Santa Catarina (com estágio de doutoramento em Harvard University, EUA (2002). Atualmente é Professor Associado III na Universidade Federal de Santa Catarina, lecionando Direito Tributário nos cursos de graduação, mestrado e doutorado em Direito.

E-mail: cleonetti37@gmail.com

Endereço profissional: Universidade Federal de Santa Catarina - Centro de Ciências Jurídicas - Campus Universitário-Trindade. CEP:88040970-Florianópolis, SC-Brasil. 